\title{
Student's Comprehension for Basic Concepts Sports Education Adaptive Physical Education in Yogyakarta State University
}

\author{
Pasca Tri Kaloka ${ }^{1, *}$ Sugeng Purwanto ${ }^{1,}$ Putri Prastiwi ${ }^{1,}$ Yuyun Ari Wibowo ${ }^{1}$ \\ ${ }^{I}$ Faculty of Sport Sciences, Universitas Negeri Yogyakarta, Yogyakarta, Indonesia \\ *Corresponding author.Email: p.trikaloka@uny.ac.id
}

\begin{abstract}
Children with special needs to be given special behavior in learning in inclusive schools, it is necessary to prepare learning plans that can be used for children with special needs in schools. It is necessary to provide understanding and learning for students about learning children with special needs in inclusive schools. This research was conducted on students of Sports Education, Yogyakarta State University with a total of 47 students as research subjects. The data analysis technique used in this research is according to the stages of the research conducted or selected by the researcher using the survey method. The results showed that of the 47 respondents who were given the questionnaire, $93 \%$ were obtained in the "adequate" category. This shows that Adaptive Physical Education textbooks really need to be made because references to Adaptive Physical Education materials are still very limited. It is hoped that the Adaptive Physical Education book will be able to help add references and insights to the handling of learning activities for Adaptive Physical Education for Children with Special Needs.
\end{abstract}

\section{Keywords: Textbooks, Adaptive Education Learning, Students}

\section{INTRODUCTION}

Learning is a knowledge construction. A person's learning mind is built based on schemata that already exist in him which are connected with experience as reinforcement [1]. Knowledge is constructed by students by organizing experiences consisting of schemata that already exist in them.

There are several ways to increase interest in learning adaptive physical education, including using innovative learning models and problem-based modules [2]. Thus, efforts to increase student interest in learning can be done by presenting more interesting textbook material.

The available teaching materials in the form of textbooks are written based on the knowledge and opinions of the authors without paying attention to the interests, motivations [3], and the level of students' abilities. As a result, these textbooks cannot increase understanding of the concept to the fullest. In fact, sometimes the textbooks used are only in the form of narratives that do not have a meaningful effect so that students are only presented with material in the form of memorization. Presentations like this cause students to learn passively.
Students' learning interest in adaptive physical education can be seen from students' responses to the given task [4]. Enrichment tasks are given to improve understanding of concepts and help students to retain knowledge longer. However, the student's response to the given task only moved the explanation from the textbook to the worksheet [5]. These results indicate that students' understanding of the material provided is still low, because students who have a good understanding of concepts tend to give answers in their own language and according to their respective understandings.

Adaptive physical education learning in the Department of Sports Education does not yet have a standard reference book used by every lecturer. Therefore, each lecturer has a perception of what material is important to teach. This has an impact on the material received by students will be different.

In the Department of Sports Education, textbooks that become references tend to prioritize acceleration by providing examples of problems with mathematical solutions compared to planting concepts. As a result, the knowledge that students have from previous learning experiences seems to be separated from the newly received knowledge. Actions taken by lecturers so that assimilation occurs between old knowledge and 
new knowledge to form students' conceptions cannot be carried out optimally. Therefore, the new knowledge gained by students as a result of the assimilation process from prior knowledge and new experiences does not materialize in students [6].

In general, there are two factors that influence the conception of students, namely internal factors and external factors [7]. Textbooks that are used as a source of student learning affect students' conceptions which is one of the external factors. The use of language that is difficult for students to understand can be an obstacle to students' conceptions and can even cause misconceptions.

Based on the description above, it is necessary to develop a textbook for the concept of adaptive physical education that can meet the learning needs and characteristics of students. The characteristics of the present material in various formats so that they can help all students in low, medium, or high clusters, the language used is easy to understand and does not cause misconceptions, and trains students' thinking skills so that the material can be delivered [8].

\section{METHODS}

Data collection was obtained through a questionnaire that was formulated based on theory and expert opinion and filled in by respondents which was then processed into information. Respondents who were involved in data collection were 47 students, namely 8 PGSD students, 37 from PJKR students, 1 Physical Education student S2 Intake, and 1 Postgraduate Physical Education student. Measurements were made on respondents using a Likert scale with a score of $5=$ strongly agree, score 4 $=$ agree, score 3 = quite agree, score 2 = disagree, and score 1 = strongly disagree.

The study implemented a survey design on physical education major in Yogyakarta state university. Data collection was taken from a questionnaire distributed to physical education students at Yogyakarta State University who had attended Adaptive Physical Education lectures, then it would be seen from the understanding and motivation of students in the learning.

The data collection technique used is a questionnaire. In this study, the data collection tool used was a questionnaire sheet.

In this study a questionnaire was used to collect information from students and physical education teachers. This questionnaire consists of multiplechoice questions using a four-point scale developed from the results of a theoretical study, in addition to disclosing data through a questionnaire.

Instruments for students that have been validated by the validator are tested with the attached results.
The test results were analyzed using the SPSS for widows version 24.0 program package, showing Kasier Mayer Olkin regarding the measure of sampling adequacy (KMO MSA) for all items of 0.536 with a significance of 0.00 . From the Rotated Component Matrix table, it is known that values below 0.5 are 4 items, namely numbers $20,26,32$, and 40 , then these four items are not carried out in data collection.

\section{RESULTS}

The total observation score from the data of 47 respondents was 2396 (93\%) from the expected score of $2585(100 \%)$. Based on the criteria in the feasibility table according to Arikunto (2009: 4), the percentage of the total score is included in the Eligible category. The presentation of the scale according to the percentage of the total score according to Arikunto (2009: 44) in detail can be described as shown in Figure 1 below:

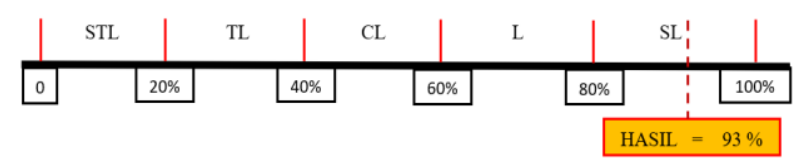

Figure 1. Test Result Eligibility Category Scale Respondent

Table 1. Questionnaire

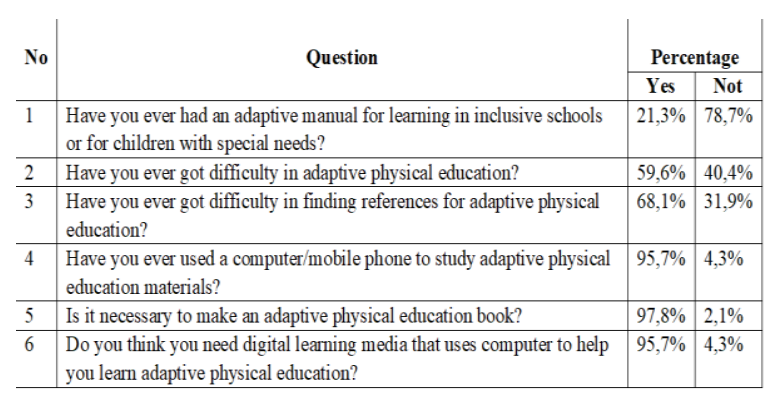

\section{CONCLUSION}

Based on the results of the questionnaire test as shown in the table, which was carried out on 47 respondents, the results obtained were that:

In the first question item, it was found that 10 respondents answered YES with a percentage (21.3\%) and 37 respondents answered NO with a percentage (78.7\%). The second item shows that 28 respondents answered YES with a percentage $(59.6 \%)$ and 19 respondents answered NO with a percentage (40.4\%). In the third item, it was found that 32 respondents answered YES with a percentage $(68.1 \%)$ and 15 respondents answered NO with a percentage (31.9\%). The fourth item showed that 45 respondents answered 
YES with a percentage $(95.7 \%)$ and 2 respondents answered NO with a percentage $(4.3 \%)$. In the fifth item, it was found that 46 respondents answered YES with a percentage $(97,8 \%)$ and 1 respondent answered NO with a percentage $(2.1 \%)$. In the sixth item, it was found that 45 respondents answered YES with a percentage $(95.7 \%)$ and 2 respondents answered NO with a percentage $(4.3 \%)$

Based on the initial data that has been obtained, it can be seen that the book on Adaptive Physical Education is very necessary to be made or held, because the references for Adaptive Physical Education materials are still very minimal. It is hoped that the existence of adaptive physical education books will be able to add references and insights to the handling of Physical Education activities for ABK

\section{ACKNOWLEDGMENT}

Based on the discussion and research results, it can be concluded that the procurement and preparation of Adaptive physical education books are very much needed, because references to adaptive physical education materials are still very minimal. It is hoped that the existence of adaptive physical education books will be able to add references and insights to the handling of physical education activities for children with special needs.

\section{REFERENCES}

[1] Braga, L., Jones, E., Bulger, S., \& Elliott, E. Empowering teachers to implement innovative content in physical education through continuous professional development. Teacher Development, 21(2), 288-306. 2017. https://doi.org/10.1080/13664530.2016.1235608

[2] Correia, V., Carvalho, J., Araújo, D., Pereira, E., \& Davids, $\mathrm{K}$. Principles of nonlinear pedagogy in sport practice. Physical Education and Sport Pedagogy, 24(2), 117-132. 2019. https://doi.org/10.1080/174088989.2018.1552673

[3] Dellantonio, S., \& Pastore, L. Ignorance, misconceptions and critical thinking. Synthese, 198(8), 7473-7501. 2021. https://doi.org/10.1007/s11229-019-02529-7

[4] Jaakkola, T., Yli-Piipari, S., Barkoukis, V., \& Liukkonen, J. Relationships among perceived motivational climate, motivational regulations, enjoyment, and PA participation among Finnish physical education students. International Journal of Sport and Exercise Psychology, 15(3), 273-290. 2017. https://doi.org/10.1080/1612197X.2015.110020

[5] Davis, J. P., \& Bellocchi, A. Objectivity, subjectivity, and emotion in school science inquiry. Journal of Research in Science Teaching, 55(10), 1419-1447. 2018. https://doi.org/10.1002/tea.21461

[6] Moy, B., Renshaw, I., \& Davids, K. The impact of nonlinear pedagogy on physical education teacher education students' intrinsic motivation. Physical Education and Sport Pedagogy, 21(5), 517-538. 2016. https://doi.org/10.1080/17408989.2015.1072506

[7] Shin, J., Kim, MS, Hwang, H., \& Lee, BY. Effects of intrinsic motivation and informative feedback in service-learning on the development of college students' life purpose. Journal of Moral Education, 47(2), 159-174. 2018. https://doi.org/10.1080/03057240.2017.1419943

[8] Zhang, T., Chen, A., \& Ennis, C. Elementary school students' nave conceptions and misconceptions about energy in physical education context. Sport, Education and Society, 24(1), 25-37. 2019. https://doi.org/10.1080/13573322.2017.1292234 